\title{
Hepatocellular carcinoma associated with pregnancy about 2 cases at the gynecological and obstetrical clinic of the Aristide Le Dantec hospital, Dakar, Senegal
}

\author{
Abdoulaye Diakhate*, Omar Gassama, Mohamed Diadhiou, Simon B. Ndour, \\ Mouhamadou Wade, Daba Diop, Adja M. Wade, Ndama Niang, Mame D. N. Guèye, \\ Mamour Guèye, Jean Charles Moreau
}

Department of Obstetrics and Gynecology, Aristide Le Dantec University Hospital Center, Dakar, Senegal

Received: 19 June 2020

Accepted: 07 December 2020

\section{*Correspondence:}

Dr. Abdoulaye Diakhate,

E-mail: lay.diakhate@gmail.com

Copyright: (c) the author(s), publisher and licensee Medip Academy. This is an open-access article distributed under the terms of the Creative Commons Attribution Non-Commercial License, which permits unrestricted non-commercial use, distribution, and reproduction in any medium, provided the original work is properly cited.

\begin{abstract}
The objective of our study was to report 2 cases of hepatocellular carcinomas associated with pregnancy followed in our structure and to review the literature. Our patients were 30 and 37-year-old multi-gesture females with chronic unattended viral hepatitis B in whom the diagnosis of hepatocellular carcinoma was made in the third trimester of pregnancy at 31 weeks of amenorrhea and 4 days and at 32 weeks of amenorrhea after the incidental finding of tumor hepatomegaly on abdominal-pelvic ultrasound. The main clinical signs were jaundice and hepatomegaly and paraclinical signs were dominated by hepatic cytolysis and anemia in addition to ultrasound images. Follow-up of pregnancies revealed no particularities. A caesarean section was scheduled at 32 weeks of amenorrhea and 32 weeks of amenorrhea and 3 days allowing the birth of two preterm newborns weighing 1210 and 1500 gm with Apgar scores of $8-10 / 10$ and 7-9/10 respectively at the fifth minute. The immediate post-operative follow-up was simple. However, the maternal-fetal prognosis was poor with the death of both patients in a multi-visceral failure table occurring respectively at 6 weeks and 3 weeks after caesarean section. The newborns had died 8 days after birth. Although rare, these two cases challenge any obstetrician to think about liver cancer in pregnant women, especially those with chronic hepatitis B. Ultrasound examination of the liver, or even better, the MRI, which is more efficient, in order to suspect early on a possible liver cancer. Indeed, early diagnosis and a thorough medical approach are essential for the treatment of HCC in pregnant patients.
\end{abstract}

Keywords: Hepatocellular carcinoma, Pregnancy, Liver cancer, Viral hepatitis B

\section{INTRODUCTION}

Hepatocellular cancer (HCC) accounts for $90 \%$ of all primary liver cell cancers worldwide. ${ }^{1}$ It is the fifth most common cancer in the world. The incidence of HCC is particularly high in parts of Asia and Africa, but has also increased over the past decade in the United States and Northern Europe. ${ }^{2}$ The association of pregnancy with cancer is a rare occurrence, especially $\mathrm{HCC}^{3}$ Indeed, there is hypo fertility in patients with liver cancer, most often linked to associated cirrhosis. ${ }^{4}$ The incidence of
HCC associated with pregnancy is estimated at $1 / 100,000$ and is mainly found in Africa and Asia. ${ }^{2,5}$ There is controversy about this association, which would be more aggressive than in non-pregnant women because of the high level of hormones during pregnancy. ${ }^{5}$ According to a review of the literature, Choi et al noted 48 cases reported worldwide up to $2011 .^{2}$ We report two observations of patients followed at the gynecological and obstetrical clinic of the Aristide Le Dantec hospital for association of pregnancy and $\mathrm{CHC}$. 


\section{CASE REPORT}

We report 2 cases of hepatocellular carcinoma associated with pregnancy collected at the gynecological and obstetrical clinic of the Aristide Le Dantec university hospital center.

\section{First case}

\section{Clinical}

It was a $5^{\text {th }}$ gesture, $3^{\text {rd }}$ pare of 30 years old, referred from the Roi Baudouin hospital center for hepatocellular carcinoma on a pregnancy estimated at 31 weeks of amenorrhea and 4 days.

In her history, she is $4^{\text {th }}$ gesture- $2^{\text {nd }}$ pare with 2 live and healthy children born by the vaginal route, aged 12 and 2 years old, and three repeated early spontaneous abortions. She has a chronic HBs antigen carrier diagnosed 2 years ago but not followed up. The current pregnancy was the $5^{\text {th }}$, followed by two prenatal consultations. On entry the patient complained of abdominal and pelvic pain. The general examination had found a general state preserved with a conjunctival sub icterus. In addition, we noted a voluminous stony hard hepatomegaly associated with collateral venous circulation. The obstetrical examination noted an ovoid uterus with a long longitudinal axis with a uterine height measured at $27 \mathrm{~cm}$, and fetal heartbeat sounds of 147 beats/min.

\section{Paraclinical}

Prenatal outcome was marked by a positive HBs antigen test and a fasting blood glucose level in the first trimester of $0.98 \mathrm{~g} / \mathrm{L}$ suggesting gestational diabetes. An early ultrasound revealed a mono-embryonic intrauterine pregnancy with 10 weeks of amenorrhea, which allowed the pregnancy to be dated at 31 weeks of amenorrhea and 4 days. Abdominal ultrasonography revealed a dysmorphic hepatomegaly with multiple macro and micro nodules, a spleen of normal size and a free peritoneum. During prenatal follow-up, an obstetrical ultrasound revealed an evolving intrauterine mono-fetal pregnancy at 29 weeks of amenorrhea and 6 days with severe anamnios and normal vascular Doppler. The biologic workup had revealed hepatic cytolysis with an aspartate amino-transferase (ASAT) level of 333.68 (X10N) and an alanine amino-transferase (ALAT) level of $71.9(\mathrm{X} 2 \mathrm{~N})$ and moderate anemia at $8.9 \mathrm{~g} / \mathrm{dl}$. Creatinine levels were normal. The blood ionogram showed hypokalemia (2.4 $\mathrm{mEq} / \mathrm{L})$ with hyponatremia $(132 \mathrm{mEq} / \mathrm{L})$ and hypochloremia $(97 \mathrm{mEq} / \mathrm{L})$. Fasting blood glucose was $1.02 \mathrm{~g} / \mathrm{L}$.

\section{Therapeutic}

The patient was hospitalized. She received antenatal corticosteroid therapy with betamethasone $12 \mathrm{mg}$ intramuscularly at 24-hour intervals. Analgesic therapy with intravenous tier II analgesics and fluid and electrolyte correction in collaboration with the anesthetists and hepato-gastroenterologists were administered to the patient. Fetal extraction was performed by caesarean section at 32 weeks of amenorrhea allowing the birth of a live female newborn weighing $1210 \mathrm{gm}$ with an Apgar score of 8/10 and 10/10 respectively at the $1^{\text {st }}$ and $5^{\text {th }}$ minute. The newborn was admitted to the neonatal unit.

\section{Evolution}

The immediate aftermath of the operation was simple. The patient was discharged after 5 days of hospitalization with a referral for follow-up in hepato-gastroenterology. The patient died 6 weeks after delivery in a multi visceral failure table. The newborn died in neonatology within one week of birth.

\section{Second case}

\section{Clinical}

It was a $5^{\text {th }}$ gesture, $4^{\text {th }}$ pare of 37 years old, referred from the hospital center Youssou Mbargane Diop of Rufisque for hepatomegaly on a pregnancy estimated at 32 weeks of amenorrhea. In her antecedents, she would be G4P4 with four live healthy children born through the vaginal route. The current pregnancy was the $5^{\text {th }}$, followed by a prenatal consultation. The prenatal check-up was marked by severe anemia at $6.3 \mathrm{~g} / \mathrm{dl}$. HBsAg testing was not done. Three ultrasound scans were performed, including one at 08 weeks of amenorrhea, which allowed the pregnancy to be dated at 32 weeks of amenorrhea. At the entrance, the patient complained of epigastralgia. The examination had found a fair general state with pale icteric mucous membranes, a blood pressure of 160/110 $\mathrm{mmHg}$ without edemas in the lower limbs with two albumin crosses in the urine at the urinary strip evoking pre-eclampsia. Abdominal examination revealed a distended abdomen with collateral venous circulation and a voluminous stony hard hepatomegaly with a tumor-like appearance. Obstetrical examination revealed an ovoid uterus with a long longitudinal axis with a uterine height measured at $26 \mathrm{~cm}$ and fetal heartbeats of 127 beats per minute. At vaginal touch, the cervix was posterior, halflong, softened, admitting the finger with intact membranes, a mobile cephalic presentation of the common discharge to the fingertip.

\section{Paraclinical}

The biological assessment had revealed a microcytic hypochromic anemia with a hemoglobin level of $6.5 \mathrm{~g} / \mathrm{dl}$, hyperleukocytosis at $63000 / \mathrm{mm}^{3}$, a hematocrit level of $21 \%$, 24-hour proteinuria at $2.02 \mathrm{gm}$, ASAT level at $51.26 \mathrm{IU}$ and ALAT level at $22.83 \mathrm{IU}$ and a positive serology of viral hepatitis B. Abdominal and pelvic ultrasound revealed a voluminous tissue mass developed at the expense of the left liver evoking HCC associated 
with a progressive single-fetal intrauterine pregnancy of 30 weeks of amenorrhea and 2 days with a weight estimate of $1600 \mathrm{gm}$ and oligoamnios.

\section{Therapeutic}

As a guideline, a blood transfusion iso group iso rhesus and administration of Nicardipine were given, as well as antenatal corticosteroid therapy with betamethasone at two doses of $12 \mathrm{mg}$ intramuscularly spaced 24 hours apart and analgesic treatment with Tramadol. After 3 days of hospitalization, a caesarean section was performed at 32 weeks of amenorrhea and 3 days allowing the extraction of a male newborn weighing 1500 gm with an Apgar score of 7/10 then 9/10 respectively at the first and fifth minute.

\section{Evolution}

The immediate aftermath of the operation was simple. The patient was discharged after 10 days of hospitalization with a referral for follow-up in hepatogastroenterology. The patient died 3 weeks after delivery in a multi visceral failure table. The newborn died in neonatology within one week of birth.

\section{DISCUSSION}

\section{Clinical}

Our two patients were 30 and 37 years old. Ndubuda et al had a mean age of 28.2 years with extremes of 22 and 37 years. ${ }^{6}$ Fracs et al recovered a mean age of 31 years. ${ }^{5}$ In addition to their age, the risk factors found in our patients were increasing gestational age and parity, and chronic viral hepatitis B carriage. Indeed, the distribution of HCC often follows the prevalence of hepatitis $\mathrm{B} .^{7} \mathrm{HCV}$ is also implicated in the development of $\mathrm{HCC}$, but it differs from HBV because vertical transmission is rare and HCC occurs approximately 10 years later in $\mathrm{HCV}$ patients than in HBV patients. ${ }^{8}$ Thus, it seems unlikely that HCVinduced $\mathrm{HCC}$ will occur in patients of childbearing age. Choi et al found no HCV patients but $64.7 \%$ of patients were positive for AghbS. ${ }^{2}$ Indeed, according to some authors, estrogens may promote malignancy of liver cell adenomas and accelerate the growth of HCC. ${ }^{9}$ However, others have found no significant correlation between the use of oral contraceptives and the development of HCC. ${ }^{10}$ Our patients have never been on estrogen-progestin contraception.

The diagnosis of HCC was made in our patients in the third trimester of pregnancy following the incidental discovery of tumor-like hepatomegaly on abdominalpelvic ultrasound. Diagnosis is most often made at an average of 24 weeks of amenorrhea with a median of 27 weeks of amenorrhea. ${ }^{2}$

Clinical signs were dominated by jaundice and tumor-like hepatomegaly which were consistent in both patients.
Indeed, hepatomegaly is one of the most frequently encountered symptoms. ${ }^{11}$ Jaundice occurs in 5 to $44 \%$ of cases. $^{11,12}$

Our two patients had comorbidities: preeclampsia for one and gestational diabetes for the other.

The obstetrical examination was unremarkable.

\section{Paraclinical}

For biological signs, anemia was constantly being found. Hepatic cytolysis was found in one patient while the hepatorenal assessment was normal in the other. Russel et al found a slight increase in liver enzymes in his study, in line with the conclusions of Vecchia et al. ${ }^{13,14}$ In our patients, alpha fetoprotein (AFP) testing could not be performed because it was not available. However, the use of AFP for HCC screening is controversial and is probably even less reliable in pregnant women than in non-pregnant women. ${ }^{15,16}$ In pregnant women, AFP levels may vary in each trimester of pregnancy, with a range of 10-614 ng/mL during a normal pregnancy. ${ }^{17-19}$ AFP levels are also influenced by maternal weight, ethnic group, age, and presence of diabetes. ${ }^{19}$ In addition, HBsAg-positive patients may have higher AFP levels than HBsAgnegative patients. Therefore, it is difficult to assume a significant value for AFP levels in HBsAg-positive patients. $^{20}$

Abdominal ultrasound revealed tumor-looking hepatomegaly and an active intrauterine pregnancy with insufficient amniotic fluid. Indeed, ultrasound is very important for the diagnosis of HCC. ${ }^{21}$ Its sensitivity for identifying liver tumors is $90 \% .^{22}$ US has the advantage of distinguishing between cystic and solid lesions and distinguishing a single mass from one with multiple satellite lesions, but it has limitations with respect to reliably differentiating between solid liver masses. ${ }^{22}$ Nevertheless, its high sensitivity and safety for the fetus make abdominal US a good initial diagnostic method. MRI is also recommended because the diagnosis of a liver mass can be hard to confirm using only abdominal US. ${ }^{22}$ In addition, MRI can distinguish most solid liver masses. However, it must be applied without contrast in pregnant women because MRI contrast agents can pass through the placental barrier and cause fetal problems such as post implantation fetal loss and growth retardation. ${ }^{22}$ Percutaneous biopsy can be used when a diagnosis cannot be made with MRI, but it is not usually recommended because of the risk of hemorrhage and tumor cell seeding. ${ }^{22}$

\section{Therapeutic}

The management was multidisciplinary, involving obstetrician, hepato-gastroenterologist, anesthetist and pediatrician. A caesarian section was performed in both patients after blood transfusion and fetal lung maturation. The newborns were 1210 and 1500 gm premature babies 
with good Apgar scores who were managed in neonatology. The choice between continuing and terminating the pregnancy presents a difficult problem for both the patient and doctor. In cases that are diagnosed early, termination of the pregnancy may be the more appropriate choice, whereas in cases diagnosed late, beginning therapy after induced delivery or caesarian section may be preferable. ${ }^{2}$ Yet this issue may be very complicated during the typical period of fetal lung maturation. There are no preferred therapies for this condition, but if it is possible and it does not cause a serious delay, then vaginal delivery followed by curative resection seems to be the most reasonable way to avoid the burden of two operations (caesarian section and liver resection). If a patient prefers not to terminate the pregnancy following an early diagnosis, then delivery after surgery may be appropriate and the patients should be informed that spontaneous abortion is a risk of such surgery. ${ }^{2}$

\section{Evolution}

The immediate post-operative follow-up was simple for both our patients, with the operation being performed on the fifth and tenth day of the postpartum period, accompanied by a referral to oncology. Unfortunately, our patients died at three and six weeks after delivery. Indeed, the prognosis for this association remains bleak with a mortality rate of almost $100 \% .^{1}$ In fact, HCC is more aggressive in pregnant women than in non-pregnant women, with an overall one-year survival rate of only $23 \% .^{23}$ This is thought to be related to the decrease in immunity caused by pregnancy and the acceleration of tumor growth with increasing estrogen levels. ${ }^{24}$ The idea that pregnant women with HCC have a worse prognosis than non-pregnant women with HCC was proposed many years ago. Several authors noted reduced survival for pregnant women with $\mathrm{HCC}$ and they assumed that pregnancy was an adverse factor for patients with HCC. ${ }^{5,25-27}$ In terms of the pathogenesis, the concept that $\mathrm{HCC}$ in pregnancy is different from that in the nonpregnant state originated from reports on the relationship between sex hormones and cancer. Since the 1970s, many authors have been interested in the correlation between oral contraceptives and liver tumors. This subject has proven to be a source of heated debate. Many reports indicate that estrogen may promote malignancy in liver cell adenomas and can accelerate the growth of HCC. ${ }^{9}$ On the other hand, other reports have indicated no significant correlation between oral contraceptive use and the development of HCC. ${ }^{10}$ In our study, our patients were never exposed to oral contraceptives. The short delay between the end of the pregnancy and the death of the patients is indicative of the advanced stage at which the diagnosis was made.

Furthermore, neonatal mortality is thought to be due to great prematurity and lack of adequate neonatal resuscitation units.

\section{CONCLUSION}

The association of pregnancy with hepatocellular carcinoma is a rare event. The risk factor found in both patients was chronic viral hepatitis B carrier. The clinical picture was dominated by tumor hepatomegaly and jaundice. On the paraclinical level, ultrasound was the most important element. The management is multidisciplinary, associating obstetrician, hepatogastroenterologist, anesthetist and pediatrician. Although rare, these two cases challenge any obstetrician to think about liver cancer in pregnant women, especially those with chronic hepatitis B. Thus, the search for HBs Antigen carrier must be systematic in all pregnant women and in case of positivity, insist on clinical and ultrasound examination of the liver, or even better, the MRI, which is more efficient, in order to suspect early on a possible liver cancer. Indeed, early diagnosis and a thorough medical approach are essential for the treatment of HCC in pregnant patients.

\section{ACKNOWLEDGMENTS}

Authors would like to thank to all the staff of the gynecological and obstetric clinic of the Aristide Le Dantec university hospital, Dakar, Senegal.

\section{Funding: No funding sources \\ Conflict of interest: None declared \\ Ethical approval: Not required}

\section{REFERENCES}

1. Trichopoulos D. Etiology of primary liver cancer and the role of steroidal hormones (editorial). Cancer Cases Controls. 1992;3:3-5.

2. Choi K, Ju Hong Y. Hepatocellular carcinoma during pregnancy: is hepatocellular carcinoma more aggressive in pregnant patients? J Hepatobiliary Pancreat Sci. 18:422-31.

3. Egwuatu V. Primary hepatocarcinoma in pregnancy. Trans Royal Soc Trop Med Hyg prednancy. 1980;74:793-4.

4. Alison M. Liver Stem Cells: Implications for hepatocarcinogenesis. Stem Cells Rev. 2005;1(3):253-60.

5. Lau W, Leng W, Ho S. Hepatocellular Carcinoma during pregnancy and its comparison with other pregnancy-associated malignancies. Cancer. 1995; 75:2669-76.

6. Ndubuda D, Makinde O, Ojo O. Hepatocellular carcinoma in pregnancy and postpartum period: a study of 6 cases in Nigerian women. J Clin Pract. 2004; 7:46-9.

7. Esike Chidi O, Ezeonu Paul O, Umeora Odidika U. Le carcinome hépatocellulaire pendant la grossesse, un cancer rare qui survient encore pendant la grossesse-une revue de la littérature. Int J Clin Obstet Gynaecol. 2020;4(2):04-6.

8. Lee H, Kim C. Association étiologique prédominante $\mathrm{du}$ virus de l'hépatite $\mathrm{C}$ avec le carcinome 
hépatocellulaire par rapport au virus de l'hépatite B chez les patients âgés dans une zone d'endémie de l'hépatite B. Cancer. 1993;72:2564-7.

9. Klatskin G. Hepatic tumors: possible relationship to use of oral contraceptives. Gastroenterol. 1977;73:386-94.

10. Heinemann L, DoMinh T, Guggenmoos-Holzmann I. Oral contraceptives and liver cancer. Results of the Multicentre International Liver Tumor Study (MILTS). Contracep. 1997;56:275-84.

11. Alireza N, Mohammad N. Hepatocellular carcinoma in pregnancy with unusual presentations. Middle East J Dig DIS. 2012;4(4):228-31.

12. Lai E, Lai P, Lau W. Soft tissue case 52. Hepatocellular carcinoma with tumour cast in the biliary tree. Canad J Surg. 2003;46:301-11.

13. Russell P, Sanjay P, Dirkzwager I. Carcinome hépatocellulaire pendant la grossesse: étude de cas et revue de la littérature. Journal médical de NouvelleZélande. 2012;125:1353.

14. La vecchia $C$, Altieri A, Franceschi S, Tavani A. Oral contraceptives and cancer: An update. Drug Safety. 2001;24:741-54.

15. Sherman M. Alphafetoprotein: une nécrologie. J hepatol. 2001;34:603-5.

16. Trevisani F, D’Intino P. Alpha-foetoprotéine sérique pour le diagnostic nez de carcinome hépatocellulaire chez les patients atteints de foie chronique maladie: influence de l'HBsAg et du statut anti-VHC. J hepatol. 2001;34:570-5.

17. Seppl M. Alpha dans le sérum maternel: a nouveau marqueur pour la détection de la détresse foetale et de la mort intra-utérine. Suis J Obstet Gynecol. 1973;115:48-52.

18. Caballero C, Vekemans M, Lopez del Campo J. Alpha-foetoprotéine sérique chez l'adulte, la femme pendant la grossesse, enfants à la naissance et pendant la première semaine de vie: une différence de sexe. Suis J Obstet Gynecol. 1977;127:384-9.

19. Mizejewski G. Niveaux d'alpha-foetoprotéine pendant la grossesse et petite enfance dans les états normaux et pathologiques. Obstet Gynecol Surv. 2003;58:804-26.

20. Lee H, Chung Y, Kim C. Spécificités de l'alpha sérique fétoprotéine dans $\mathrm{HBsAgS}+$ et $\mathrm{HBsAg}$ patients dans le diagnostic de carcinome hépatocellulaire. Hépatologie. 1991;14:68-72.

21. Ai-Jun L, Wei-Ping Z, Jun-hau L. Surgery for pregnancy-associated primary hepatocellular carcinoma. Report of four cases. Int J Surg Case Reports. 2014;5(2):882-5.

22. Cobey F, Salem R. A review of liver masses in pregnancy and a proposed algorithm for their diagnosis and management. Am J Surg. 2004;187:181-91.

23. El-Serag H. Carcinome hépatocellulaire. N Engl J Med. 2011;365(111):8-27.

24. Jonas M. Hepatitis B. pregnancy: an underestimated issue. Liver Int. 2009;29:133-9.

25. Jeng L, Lee W, Wang C. Hepatocellular carcinoma in a pregnant woman detected by routine screening of maternal alpha-fetoprotein. Am J Obstet Gynecol. 1995;172:219-20.

26. Gisi P, Floyd R. Hepatocellular carcinoma in pregnancy. case reports. J Reprod Med. 1999;44:65-7.

27. De la Rosa M, Nicols-Prez D, Muiz-Montes J. Evolution and management of a hepatocellular carcinoma during pregnancy. J Obstet Gynaecol Res. 2006;32:437-9.

Cite this article as: Diakhate $A$, Gassama $O$, Diadhiou M, Ndour SB, Wade M, Diop D, et al. Hepatocellular carcinoma associated with pregnancy about 2 cases at the gynecological and obstetrical clinic of the Aristide Le Dantec hospital, Dakar, Senegal. Int J Reprod Contracept Obstet Gynecol 2021;10:353-7. 